\title{
In Vivo Emulsification Analysis of 1000 cs and 5000 cs Silicone Oil after Rhegmatogenous Retinal Detachment Vitrectomy Surgery
}

\author{
Arief Kartasasmita, Widi Kusdiono, Rova Virgana, Shanti Boesorie \\ Department of Ophthalmology, Faculty of Medicine, Universitas Padjadjaran/Cicendo National Eye Hospital, Bandung, Indonesia \\ Email: a.kartasasmita@unpad.ac.id
}

How to cite this paper: Kartasasmita, A., Kusdiono, W., Virgana, R. and Boesorie, S. (2017) In Vivo Emulsification Analysis of $1000 \mathrm{cs}$ and $5000 \mathrm{cs}$ Silicone Oil after Rhegmatogenous Retinal Detachment Vitrectomy Surgery. Open Journal of Ophthalmology, 7, 231-239.

https://doi.org/10.4236/ojoph.2017.74031

Received: August 6, 2017

Accepted: September 26, 2017

Published: September 29, 2017

Copyright $\odot 2017$ by authors and Scientific Research Publishing Inc. This work is licensed under the Creative Commons Attribution International License (CC BY 4.0).

http://creativecommons.org/licenses/by/4.0/

(c) † Open Access

\begin{abstract}
Purpose: To compare in vivo emulsification of silicone oil 1000 and 5000 centistokes (cs) after retinal detachment surgery. Design: Comparative non-interventional Retrospective study. Methods: Silicone oils from patients who underwent retinal detachment surgery were investigated using Spectrophotometer UV-Vis. Spectroscopically changes determine emulsification with the time of tamponade, inflammation, patients age and severity of retinal detachment. Results: We found significant difference on absorbance $(\mathrm{p}=0.004)$ between used 1000 Centi stoke (cs) silicon oil (average wave length $2.51 \mathrm{~nm}$; SD: $1.575 \mathrm{~nm}$ ) and used $5000 \mathrm{cs}$ silicon oil (average wave length $0.910 \mathrm{~nm}$; SD: $0.564 \mathrm{~nm}$ ). Conclusions: In vivo emulsification was higher in silicone oil 1000 compared to 5000 cs silicone oil after vitreoretinal tamponade $8-12$ weeks due to retinal detachment surgery. Emulsification related to higher absorbance and lower transmittance in $1000 \mathrm{cs}$ silicone oil. Inflammation may become a factor affecting this condition.
\end{abstract}

\section{Keywords}

Silicone Oil, Spectrophotometry, Emulsification

\section{Introduction}

Silicone oils were used in retinal detachment surgery since 1962 and had been used increasingly especially in complicated cases such as retinal detachment with severe proliferative vitreoretinopathy, giant retinal tears, proliferative diabetic retinopathy, viral retinitis and ocular trauma [1].

Emulsification is the most common complication in silicone oil tamponade [2]. It can lead to clinical problems such as glaucoma, keratopathy, and cataract 
formation [3]. Emulsification can be identified as droplet formation of a small bubble of silicone oil with or without opacification of the bubble. Time formation of emulsification was different from one person to another. Several authors investigated various factors which can increase the occurrence of emulsification. Inflammation, blood constituent, protein, lipid, and viscosity were identified as factors that can influence the stability of silicone oil in human eyes [2] [4] [5].

The most common used silicone oil in vitreoretinal surgery is 1000 and 5000 centi Stoke (cs). Silicone oil with viscosity 1000 cs is easier and faster to inject and remove but has limitation sooner to be emulsified compared to higher viscosity. Silicone oil $5000 \mathrm{cs}$ has lower tendency to emulsify which may provide longer tamponade effect [6] [7]. However, study showed that the $5000 \mathrm{cs}$ silicone oil may be associated with a poorer anatomic and visual outcome compared with 1000 cs silicone oil [8].

Although in vitro study showed that silicone oil with higher viscosity was more stable than lower viscosity, Soheilian et al. found that clinically, there was no difference in complications rates between 1000 vs. 5000 cs silicone oil after retinal detachment surgery [6].

The purpose of this study was to compare in vivo emulsification of silicone oil 1000 and $5000 \mathrm{cs}$ after retinal detachment surgery.

\section{Methods}

This study non-randomized comparative study to 13 silicone oil $1000 \mathrm{cSt}$ and nine silicone oil $5000 \mathrm{cs}$ was taken from patients who underwent silicon oil tamponade for 8 - 12 weeks tamponade duration. The inclusions criteria are patient with primary vitrectomy due to Rhegmatogenous Retinal Detachment (RRD) who underwent vitrectomy with silicon oil endo tamponade. The exclusion criteria are combined endo tamponade with perfluorocarbon liquid; using perfluorocarbon liquid during vitrectomy surgery; patient using steroid or anti-inflammation therapy at least three months prior the surgery. All patients had undergone retinal detachment surgery at Cicendo Eye Hospital, Indonesia. Removal of silicone oil tamponade decision was based on the attachment of retina within 8 - 12 weeks of tamponade. The silicon oil removal was done by a single operator using vitrectomy machine (Alcon Constellation Vision System, Fort Worth Texas USA). As the normal control, we compared the samples with unused 1000 and $5000 \mathrm{cSt}$ silicone oil from the same brand.

To perform Silicone oil evaluation, the samples were placed in an acrylic cuvet with dimension $4.5 \mathrm{~cm} \times 1.425 \mathrm{~cm} \times 1.425 \mathrm{~cm}$ and $1.5 \mathrm{cc}$ volume. The Spectrophotometry UV-Vis T70+ (PG Instruments Ltd) was used to evaluate absorbance and transmittance changes in both groups. Assessment of silicon oil emulsification macroscopically was done by a single operator using criteria 'fish egg' appearance on silicon oil samples. The examiner was blinded to study subject. No interventions were given in this study. The statistical analysis was performed using Shapiro-Wilk test and Mann-Whitney test with $p \leq 0.05$ is consi- 
dered as significant.

\section{Result}

We collected 13 samples from the eye that tamponade using $1000 \mathrm{cs}$ silicon oil and nine samples from the eye that using $5000 \mathrm{cs}$ oil. Detail of the clinical characteristics is shown in Table 1 and Table 2. The age range of patients on $100 \mathrm{cs}$ silicon oil group was between 31 - 64 years. Respectively, 29 - 41 years range on 5000 cs group. There is statistically significant on patient's age between the two group $(\mathrm{p}=0.043)$.

Duration of tamponade on the two groups is between $8-12$ weeks with average 9.9 weeks in group 1, and 10.6 weeks in group 2 . There is no statistical difference between the two group on tamponade duration $(p=0.202)$

Table 3 showed the clinical characteristic of retinal detachment related to silicon oil emulsification in each group. This showed that $1000 \mathrm{cs}$ silicon oil has a tendency to emulsified compare to $5000 \mathrm{cs}$.. There is no emulsification macroscopically on 5000 cs silicon oil found.

Table 4 and Table 5 showed the comparison of changes in absorbance that measure the emulsification of silicon $1000 \mathrm{cs}$ and $5000 \mathrm{cs}$ using spectrophotometry. On this result, the absorbance of 1000 cs silicon oil is higher than 5000 cs. There is statistically significant different in absorbance between two groups ( $\mathrm{p}<$ 0.005). This finding shows that in general $1000 \mathrm{cs}$ silicon oil is easier to emulsified comparing to $5000 \mathrm{cs}$ silicon oil.

\section{Discussion}

Silicone oil is an important and widely used intravitreal tamponade in vitreoretinal

Table 1. Clinical Characteristics of Patients with 1000 cs Tamponade of Silicone Oil.

\begin{tabular}{ccccc}
\hline No & $\begin{array}{c}\text { Age } \\
\text { (years) }\end{array}$ & Sex & Diagnose & $\begin{array}{c}\text { Time of Tamponade } \\
\text { (weeks) }\end{array}$ \\
\hline 1 & 40 & M & RD + PVR grade B + Aphakia & 12 \\
2 & 64 & M & RD + PVR grade B & 12 \\
3 & 39 & F & RD (3 quadrants) & 8 \\
4 & 47 & F & Total RD + SenileCataract & 8 \\
5 & 48 & M & RD & 9 \\
6 & 50 & F & RD & 12 \\
7 & 31 & M & Total RD + Traumatic cataract & 12 \\
8 & 47 & M & GRT & 8 \\
9 & 61 & M & RD & 8 \\
10 & 45 & F & RD (3 quadrants) & 12 \\
11 & 50 & M & RD & 12 \\
12 & 47 & M & RD + PVR & 8 \\
13 & 64 & M & Total RD & 8 \\
\hline & & & & \\
\hline
\end{tabular}


Table 2. Clinical Characteristics of Patients with 5000 cs Tamponade of Silicone Oil.

\begin{tabular}{ccccc}
\hline No & Age (years) & Sex & Diagnosis & Time of Tamponade (weeks) \\
\hline 1 & 39 & $\mathrm{M}$ & Total RD & 12 \\
2 & 38 & $\mathrm{M}$ & $\mathrm{RD}$ (3 quadrants) & 12 \\
3 & 30 & $\mathrm{M}$ & $\mathrm{RD}$ & 8 \\
4 & 29 & $\mathrm{M}$ & $\mathrm{RD}$ & 8 \\
5 & 58 & $\mathrm{M}$ & $\mathrm{RD}+$ Coloboma of Choroid & 12 \\
6 & 33 & $\mathrm{M}$ & $\mathrm{RD}$ (2 quadrants) & 12 \\
7 & 40 & $\mathrm{M}$ & Total RD & 12 \\
8 & 36 & $\mathrm{M}$ & Total RD + PVR grade D & 8 \\
9 & 62 & $\mathrm{~F}$ & Total RD & 12 \\
\hline
\end{tabular}

${ }^{\star} \mathrm{RD}=$ Retinal Detachments, PVR = Proliverative vitreoretinopathy, GRT = Giant Retinal Tears.

Table 3. Patient Characteristic Related to Silicon Oil Emulsification.

\begin{tabular}{|c|c|c|c|c|}
\hline \multirow{3}{*}{ Patients Characteristics } & \multicolumn{4}{|c|}{ Tamponade of Silicone Oil } \\
\hline & \multicolumn{2}{|c|}{$1000 \mathrm{cs}(\mathrm{n}=13)$} & \multicolumn{2}{|c|}{$5000 \mathrm{cs}(\mathrm{n}=9)$} \\
\hline & $\begin{array}{c}\text { Emulsification } \\
(+)\end{array}$ & $\begin{array}{c}\text { Emulsification } \\
(-)\end{array}$ & $\begin{array}{c}\text { Emulsification } \\
(+)\end{array}$ & $\begin{array}{c}\text { Emulsification } \\
(-)\end{array}$ \\
\hline \multicolumn{5}{|l|}{ 1) Sex } \\
\hline Male & 4 & 5 & 0 & 8 \\
\hline Female & 3 & 1 & 0 & 1 \\
\hline 2) Retinal Detachment (RD) & 2 & 4 & 0 & 3 \\
\hline Total RD & 2 & 0 & 0 & 4 \\
\hline $\mathrm{RD}$ & 0 & 1 & 0 & 2 \\
\hline RD with PVR & 1 & 1 & 0 & 0 \\
\hline GRT & 1 & 0 & 0 & 0 \\
\hline Total RD + History of Trauma & 1 & 0 & 0 & 0 \\
\hline \multicolumn{5}{|l|}{ 3) Age (years) } \\
\hline$<40$ & 3 & 0 & 0 & 7 \\
\hline$>40$ & 4 & 6 & 0 & 2 \\
\hline \multicolumn{5}{|l|}{ 4) Time of Tamponade (weeks) } \\
\hline$<10$ weeks & 4 & 3 & 0 & 3 \\
\hline$>10$ weeks & 5 & 1 & 0 & 6 \\
\hline
\end{tabular}

${ }^{*} \mathrm{RD}=$ Retinal Detachments, $\mathrm{PVR}=$ Proliverative vitreoretinopathy, $\mathrm{GRT}=$ Giant Retinal Tears.

surgery that is intended as a temporary tamponade for rhegmatogenous retinal detachment surgery. Based on the viscosity, there are several types of silicone oil that are used in vitreoretinal surgery. Selection of the type of silicone oil used is based on the patient's clinical condition and estimated the duration of tamponade needed [2]. 
Table 4. The Comparison of Absorbance Changes in Silicon Oil 1000 cs and 5000 cs Sample to unused Silicon Oil 1000 cs and 5000 cs.

\begin{tabular}{ccc}
\hline \multirow{2}{*}{ Absorbance } & \multicolumn{2}{c}{ Group } \\
\cline { 2 - 3 } & Silicon Oil $1300 \mathrm{cs}(\mathrm{n}=13)$ & Silicon Oil $5500 \mathrm{cs}(\mathrm{n}=9)$ \\
\hline Wave length: & 0.059 & 0.111 \\
$770 \mathrm{~nm}$ & $0.148(0.093)$ & $0.103(0.062)$ \\
Mean (SD) & 0.131 & 0.096 \\
Median & $0.049-0.357$ & $0.024-0.176$ \\
Range & $\mathrm{p}=0.005$ & $\mathrm{p}=0.699$ \\
\hline
\end{tabular}

Table 5. The Comparison of Absorbance Changes in Silicon Oil 1000 cSt and 5000 cSt Samples.

\begin{tabular}{cccc}
\hline \multirow{2}{*}{ Absorbance } & \multicolumn{2}{c}{ Group } & p-value \\
\cline { 2 - 3 } & Silicon Oil $1300 \mathrm{cs}(\mathrm{n}=13)$ & Silicon Oil $5500 \mathrm{cs}(\mathrm{n}=9)$ & \\
\hline Wave length: & & & \\
$770 \mathrm{~nm}$ & $2.51(1.575)$ & $0.910(0.564)$ & 0.004 \\
Mean (SD) & 2.22 & 0.86 & \\
Median & $0.83-6.05$ & $0.21-1.58$ & \\
Range & & & \\
\hline
\end{tabular}

The $1000 \mathrm{cs}$ and $5000 \mathrm{cs}$ silicon oil are the two type of silicon oil most used in vitreoretinal surgery. The $1000 \mathrm{cSt}$ silicone oils are easier to inject and remove from the eye but have less stable properties resulting in more frequent complications. Silicon 5000 cs oil has more stable properties when compared with 1000 cs silicone oil but is more difficult to inject and removal due to its viscosity [9].

Several factors are thought to affect changes in physical properties of silicone oils in the eyeballs such as the rheological properties of silicone oil itself, the saccadic movement of the eyes and the patient's head, the length of tamponade, and the presence of blood and inflammation components in the vitreous cavity [10].

Table 3 shows the age characteristics in both groups are slightly different. Age on a 5000 cs group is younger compared 1000 cs group. There are 7 of 9 samples from patients aged $\leq 40$ years, but the changes in absorbance (emulsification) that occur in this group is lower. In the group of $1000 \mathrm{cs}$ silicone oil, three samples from patients aged $\leq 40$ years, which all have absorbance value (degree of emulsification) higher when compared to 5000 cs silicone oil in the same age group.

The presence of inflammatory cells released in the retinal detachment can diffuse into the silicone oil [11]. This condition will cause the silicone oil absorb more surfactants that lead the damage of silicon oil structure [12]. Examination 
using spectrophotometer to damaged silicon oil showed increase in absorbance value due to the silicon oil absorb various surfactants.. This increase in absorbance value is the initial parameter of changes in silicone oil which in the later stages can lead to emulsification [13].

Silicone oil is widely used in surgery are trimethyl siloxy-terminated vitreoretinal $\mathrm{SiO}$, poly-trifluoro propyl-methylsiloxane ( $\mathrm{FsiO})$ and the most rarely used polyphenylmethylsiloxane [2]. In this study, we used only one type of silicone oil. Therefore, the silicone oil used in this study has the same rheological properties.

Vitreous samples examination of PVR patients showed an increased number of cytokines, such as interleukin-1 beta (IL-1 $\beta$ ), TNF- $\alpha$, and monocyte chemoattractant protein-1 (MCP-1). Study showed, growth factors, such as basic fibroblast Growth Factor (bFGF) in PVR patient is also higher when compared with patients with macular holes or idiopathic premacular fibrosis [14]. Some studies suggest that the macrophage will release enzyme on PVR resulting in vitreous structure changes as a result of the protein matrix proteolysis and also the formation of fibrotic membranes to synthesis the fibroblast growth factor by macrophages [15].

As a result, on the 1000 cs group showed a considerable increase in absorbance values (emulsification rates) in some samples taken from patients with rhegmatogenous retinal detachment with PVR, giant retinal tear, and total retinal detachment (samples $1,4,7,8,10,13$ ). Samples in the $5000 \mathrm{cs}$ silicone oil group with retinal detachments, total retinal detachment and retinal detachment with PVR have increased absorbance value (emulsified). However, the increasing of absorbance value in the $5000 \mathrm{cs}$ sample group did not exceed the absorbance value Silicone oil in the sample group $1000 \mathrm{cs}$. This suggests that with a risk factor of an inflammatory condition, $5000 \mathrm{cs}$ silicone oil has a more stable properties compared with 1000 cs silicone oil.

Bleeding factor is one of the factors that can accelerate the silicone oil emulsification [4] [16]. Bleeding components that have a tendency to cause emulsification based on in vitro studies are including fibrin, fibrinogen, serum, plasma, $\gamma$-globulin, and lymphocytes. Study showed that in vitro study the serum causes a slightly higher emulsification of silicone oil when compared with plasma [17]. In this study, we have no data the relation of bleeding factors to the emulsification.

In this study the duration of tamponade in the two sample groups varied, ranging from 8 - 12 weeks on based on the patient clinical conditions. Tamponade on 1000 cs silicone oil samples performed over eight weeks resulted in higher absorbance values when compared to the 5000 cs sample group. Increased absorbance values in the $5000 \mathrm{cs}$ sample group who had tamponade over eight weeks is not higher when compared to the $1000 \mathrm{cs}$ sample group at the same tamponade duration.

The duration of tamponade is one of the factors that influence the damage of 
silicone oil [18]. Several previous studies mentioned that the longer the tamponade, the possibility for emulsification will be greater. Damage to silicone oil is caused because the longer the silicone oil is inside the eyeball, the more surfactants are absorbed by the silicone oil. This will lead to an increase in the absorbance value of silicone oil. Silicone oils that have absorbed various surfactants will be more easily broken down into small molecules resulting in decreased surface tension, buoyancy and viscosity decrease. In the advanced stages of this damaged silicone oil, it is easier to migrate to the anterior segment of the eyeball or subretinal space and cause further complications [19].

Emulsification of silicone oil in the eyeball is also affected by the movement of the eyeball and the movement speed of silicone oil against the walls of the vitreous cavity. As the eye moves, the silicone oil inside the ball will also move [20]. However, this movement also depends on the viscosity of the silicone oil, the intensity of movement of the eyeball and the head; and the frequency of movement itself. Low viscosity silicone oil will have a fairly high/fast motion gradient, while silicone oil with a higher viscosity will have a slower gradient. Until recently, there is no study report the effect of the eye and head movement on emulsification, but some in vitro studies suggest that the mechanical energy imparted to silicone oil will cause the breakdown of the surface tension of silicone oil to dissipate silicon oil into small particles which are unstable. These tiny particles are easier to absorb the organic molecules present in the eyeball. In this study, the movement of the eyeball and the patient's head can be estimated by the duration of tamponade. The longer the tamponade in the patient's eyeballs, the possibility of eye movement and the head of the patient will also affect more damage to the silicone oil [10].

Factors that may affect damage to silicone oils such as the saccadic movement of the eyeball and the patient's head, the duration of tamponade and the presence of surfactants in the eyeballs are affected each other [10]. In addition to these factors, the characteristics of silicone oil also affect the damage of silicone oil. Higher viscosity silicone oils have more stable properties because they have stronger, stronger polymer bonding chains when compared to silicone oils with lower viscosity. This polymer bonding chain will limit the absorption of surfactants into silicone oil. The diffusion of the surfactant into silicone oil depends on the size of the molecule, the bond between the molecules and the nature of the molecule itself. In this study, there was an increase in absorbance (damage to silicone oil) in both groups that could be caused by the presence of inflammatory factors and the type of silicone oil used.

Absorbance $1000 \mathrm{cs}$ silicon oil is greater when compared with $5000 \mathrm{cs}$ silicone oil. Even though macroscopically there is no sign of silicone oil damage, but microscopically the physical and chemical structures changes may already there. This is evident from the increase in absorbance in both groups of samples with a larger increase occurring in the $1000 \mathrm{cs}$ silicone oil sample group.

The inflammation and blood properties were not assessed in this study. This is 
considered as the limitation of this study. Further study involving more samples is suggested to confirm findings in this study.

\section{Conclusion}

Silicon oil with $5000 \mathrm{cs}$ viscosity has better emulsification stability in tamponade to retinal detachment surgery comparing to $1000 \mathrm{cs}$ Silicon oil. Although there was no emulsification of silicone oil clinically, there were some structural changes occurring in silicone oil which was higher in silicone oil 1000 cs compared to $5000 \mathrm{cs}$.

\section{References}

[1] Azarmina, M., Soheilian, M., Azarmina, H. and Hosseini, B. (2011) Electroretinogram Changes Following Silicone Oil Removal. Journal of Ophthalmic \& Vision Research, 6, 109-113.

[2] Barca, F., Caporossi, T. and Rizzo, S. (2014) Silicone Oil: Different Physical Proprieties and Clinical Applications. BioMed Research International, 2014, Article ID: 502143. https://doi.org/10.1155/2014/502143

[3] Yusuf, I.H., Fung, T.H., Salmon, J.F. and Patel, C.K. (2014) Silicone Oil Pupil Block Glaucoma in a Pseudophakic Eye. BMJ Case Reports.

[4] Savion, N., Alhalel, A., Treister, G. and Bartov, E. (1996) Role of Blood Components in Ocular Silicone Oil Emulsification. Studies on an in Vitro Model. Investigative Ophthalmology \& Visual Science, 37, 2694-2699.

[5] Lakits, A., Nennadal, T., Fau-Scholda, C., Scholda, C., Fau-Knaus, S., Knaus, S., Fau-Gruber, H. and Gruber, H. (1999) Chemical Stability of Silicone Oil in the Human Eye after Prolonged Clinical Use. Ophthalmology, 106, 1091-1100.

[6] Soheilian, M., Mazareei, M., Mohammadpour, M. and Rahmani, B. (2006) Comparison of Silicon Oil Removal with Various Viscosities after Complex Retinal Detachment Surgery. BMC Ophthalmology, 6, 21. https://doi.org/10.1186/1471-2415-6-21

[7] Yang, A.H., Jin, W. and Xing, Y.Q. (2009) Changes in Visual Acuity, Axial Length, and Refraction after Removal of Intraocular Silicone Oil Following Retinal Reattachment Surgery in Chinese Patients: An Open-Label, Prospective Study. Current Therapeutic Research, Clinical and Experimental, 70, 221-227. https://doi.org/10.1016/j.curtheres.2009.06.002

[8] Hoerauf, H., Roider, J., Bopp, S., Lucke, K. and Laqua, H. (1995) Endotamponade with Silicon Oil in Severe Proliferative Retinopathy with Attached Retina. Oph thalmologe, 92, 657-662.

[9] Joussen, A.M., Kirchhof, B., Schrage, N., Ocklenburg, C., Hilgers, R.-D., on Behalf of the HSOSG. (2007) Heavy Silicone Oil versus Standard Silicone Oil as Vitreous Tamponade in Inferior PVR (HSO Study): Design Issues and Implications. Acta Ophthalmologica Scandinavica, 85, 623-630. https://doi.org/10.1111/j.1600-0420.2007.00898.x

[10] Chan, Y.K., Ng, C.O., Knox, P.C., Garvey, M.J., Williams, R.L. and Wong, D. (2011) Emulsification of Silicone Oil and Eye Movements. Investigative Ophthalmology \& Visual Science, 52, 9721-9727. https://doi.org/10.1167/iovs.11-8586

[11] Chinskey, N.D., Zheng, Q.D. and Zacks, D.N. (2014) Control of Photoreceptor Autophagy after Retinal Detachment: The Switch from Survival to Death. Investigative 
Ophthalmology \& Visual Science, 55, 688-695. https://doi.org/10.1167/iovs.13-12951

[12] Morescalchi, F., Costagliola, C., Duse, S., et al. (2014) Heavy Silicone Oil and Intraocular Inflammation. BioMed Research International, 2014, Article ID: 574825. https://doi.org/10.1155/2014/574825

[13] Thirumangalathu, R., Krishnan, S., Ricci, M.S., Brems, D.N., Randolph, T.W. and Carpenter, J.F. (2009) Silicone Oil- and Agitation-Induced Aggregation of a Monoclonal Antibody in Aqueous Solution. Journal of Pharmaceutical Sciences, 98, 3167-3181. https://doi.org/10.1002/jps.21719

[14] Schwarzer, H., Mazinani, B., Plange, N., Fuest, M., Walter, P. and Roessler, G. (2014) Clinical Observations and Occurrence of Complications Following Heavy Silicone Oil Surgery. BioMed Research International, 2014, Article ID: 706809.

[15] Russo, A., Morescalchi, F., Donati, S., et al. (2017) Heavy and Standard Silicone Oil: Intraocular Inflammation. International Ophthalmology. https://doi.org/10.1007/s10792-017-0489-3

[16] Ramezani, A., Ahmadieh, H., Rozegar, A., et al. (2017) Predictors and Outcomes of Vitrectomy and Silicone Oil Injection in Advanced Diabetic Retinopathy. Korean Journal of Ophthalmology, 31, 217-229. https://doi.org/10.3341/kjo.2016.0018

[17] Caramoy, A., Schroder, S., Fauser, S. and Kirchhof, B. (2010) In Vitro Emulsification Assessment of New Silicone Oils. British Journal of Ophthalmology, 94, 509-512. https://doi.org/10.1136/bjo.2009.170852

[18] Nagpal, M.P., Videkar, R.P. and Nagpal, K.M. (2012) Factors Having Implications on Re-Retinal Detachments after Silicone Oil Removal. Indian Journal of Ophthalmology, 60, 517-520. https://doi.org/10.4103/0301-4738.103777

[19] Caramoy, A., Kearns, V.R., Chan, Y.K., et al. (2015) Development of Emulsification Resistant Heavier-than-Water Tamponades using High Molecular Weight Silicone Oil Polymers. Journal of Biomaterials Applications, 30, 212-220. https://doi.org/10.1177/0885328215575623

[20] Chan, Y.K., Williams, R.L. and Wong, D. (2014) Flow Behavior of Heavy Silicone Oil during Eye Movements. Investigative Ophthalmology \& Visual Science, 55, 8453-8457. https://doi.org/10.1167/iovs.14-15439 